\title{
Correlates of Type A Behaviour Among Professionals
}

\author{
$R$ van Wyk and A B Boshoff \\ Department of Business Management, University of Pretoria
}

C L Bester

Department of Psychology, University of the Orange Free State

\section{ABSTRACT}

A review of the relevant literature indicates that a study of the relationships between Type $\mathrm{A}$ behaviour and personal as well as organizational variables is necessary. Information was gathered from 375 professionals on a number of demographic and personality variables, as well as Type $A$ behaviour. MANOVA, Product-moment correlation, and Multiple regression were used to determine the relationships between Type $A$ behaviour and other variables. Total Type A scores could be predicted reasonably well by means of personality variables. Demographic variables were less closely related to Type A scores.

JEL J 20

\section{INTRODUCTION}

High demands are currently placed on members of the working population in Western society. Such demands may lead to high strain in persons who are involved in commercial and in professional activities (Byrne, 1987). Type A behaviour may be a causal factor as well as an outcome of such a situation.

The term Type $A$ behaviour pattern was coined by two cardiology researchers, Friedman and Rosenman (1959), who identified a typical behaviour pattern presented by many of their cardiology patients.

Rosenman (1991) later defines Type A behaviour as comprising:

- specific characteristics such as ambitiousness, aggressiveness, competitiveness and impatience,

- specific muscle tense behaviour, such as alertness, rapid and emphatic vocal stylistics,

- an accelerated pace of activities, and 
- emotional responses characterized by irritation, hostility and increased potential for anger.

Type A behaviour has been extensively studied. It seems as if the interest in this field at first centered around the effects of Type A behaviour on the health of individuals (Friedman \& Rosenman, 1959; Friedman \& Rosenman, 1974; Jenkins, Zyzanski and Rosenman 1979; Adler \& Matthews, 1994). In later work the relationship between Type $A$ behaviour and a large number of other variables was examined. Among them were demographic variables like age (Friedman \& Rosenman, 1974; Blumenthal \& Herman, 1985; Helman, 1987; Byrne \& Reinhart, 1990; Jamal \& Baba, 1991), gender (Burke, 1983; Cox, 1983; Forshaw, 1984; Hicks, Olsen \& Smith-Robison, 1986; Moss, Dielman, Campanel]i, Leech. Van Harrison and Horvath, 1986; Sorenson, Jacobs, Pirie, Folsom, Luepker and Gillum, 1987; Hartell \& Chambless, 1989; Wiegele \& Oots, 1990; Bedeian, Mossholder and Touliatos, 1990; Thorenson \& Low, 1991; Greenglass, 1991; Jamal \& Baba, 1991; Gamble \& Matteson, 1992; Greenglass, 1993; Byrne \& Reinhart, 1995), marital status (Jamal \& Baba, 1991; Byrne \& Reinhart, 1995), home language (Cox, 1983; Swanepoel, 1984; Jamal \& Baba, 1991; Strümpfer, 1993), occupation (Jamal \& Baba, 1991; Byrne \& Reinhart, 1995; Strümpfer, 1995), employment situation (Strümpfer, 1993; Begley, 1995), number of years worked (Chusmir \& Hood, 1988), urban/rural background (Jainal, 1985).

The relationship between Type A behaviour and other variables that can be of importance in the work situation attracted the attention of a number of researchers. One such variable is locus of control (Wolf, Hunter, Webber and Berenson, 1981; Furnham, 1983; Feather \& Volkmer, 1988; Spector \& O'Connel, 1994; Begley, 1995; Norden, 1995; Gomez, 1997; Morrison, 1997).

The relationships that were found in these studies are generally weak. It seems as if the strongest relationship was found to be between internal locus of control and the achievement dimension of Type $A$ behaviour.

Another variable that was related to Type A behaviour is Schein's (1978) notion of career anchors or career orientations. Burke (1983) found low but significant correlation between several of the career orientations identified by Schein (1978) and scores on the Jenkins Activity Survey developed by Jenkins, Zyzanski and Rosenman (1979). In the same study differences were also found between the strength of the relationships for men and for women. In a further study Burke (1985) measured four career orientations. Significant correlation was found between these orientations and Type $A$ behaviour. 
Job involvement is another variable which attracted attention with regard to its relationship with Type $A$ behaviour, with significant correlation found between job involvement and measures of Type A behaviour (Chusmir \& Hood, 1986; Chusmir \& Hood, 1988).

Job satisfaction, being widely studied and regarded as an important organizational variable (McCormick \& Ilgen, 1985), was also correlated with Type A behaviour. Negative correlations were found between job satisfaction and Type A behaviour scores by Chismur and Hood (1988), Byme and Reinhart (1990), Gamble and Matteson (1992) and by Byrne and Reinhart (1994). Significant positive relationships were, however, found between job satisfaction and Type A behaviour by Bedeian, Mossholder and Touliotos (1991), Day and Bedeian (1991), Kushnir and Vickers (1991) and by Norden (1995). Robertson, Cooper and Williams (1990) point out that the relationship between job satisfaction and Type $\mathrm{A}$ behaviour is probably more complex than assumed in the studies quoted. Robertson et al. (1990) found in their study of 105 management consultants that the best prediction of job satisfaction was provided by the interaction between job pressure and Type A behaviour. Mugdil, Muhar and Bhatia (1992) also differentiate between low job satisfied and high job satisfied individuals who display high levels of Type A behaviour. According to Mugdil et al. (1992) individuals who are not satisfied with their jobs tend to display high levels of Type A behaviour as part of such individuals' chronic struggle to achieve goals that are poorly defined. This will not happen when individuals are satisfied with their jobs.

Anastasi (1990) states that research about the self-concept has been focused on the cumulative effect that self-evaluations have on cognitive and affective traits, which directly or indirectly influence the performance of the individual. Wolf, Hunter, Webber and Berenson (1981) and Lobel (1988) therefore studied the relationship between the self-concept and Type $A$ behaviour. The relationship appeared to be negative - higher levels of Type A behaviour tend to be associated with negative rather than positive self-concept scores.

Entrepreneurs and entrepreneurship attract considerable attention at present. Professionals have an important role to play in rendering service to society (Schein \& Kommers, 1972). The relationship between Type A behaviour and entrepreneurship has, as far as could be ascertained, not yet been studied - at least not in a sample of professionals. This however seems to be an important area for investigation (Van Wyk, 1998).

The studies that were reviewed suffered from several problems. In many cases only small samples were used. In almost all cases samples of convenience were employed. Under these circumstances the representativeness of the samples on 
which the studies were carried out must be in doubt. Taking into account the present state of statistical analysis of data, the analyses carried out in most of the studies cited were not very sophisticated. It also seems as if researchers in this field did not try to minimize error variance in the measuring instruments which they used. The results from different studies are often contradictory. The vast majority of the studies were done on samples from the North American culture.

Under the circumstances it seemed necessary to conduct a more comprehensive study in order to determine the relationships of different variables with Type A behaviour more precisely. As professional people form a very important group in society (Schein \& Kommers, 1972; Gamble \& Matteson, 1992) it was decided to do the study on members of two professional groups.

\section{METHOD}

\section{Sample}

The sample consisted of 221 men with a mean age of 45.72 years $(S D=12.79$, Range $=22$ to 84$)$ and 154 women with a mean age of 35.70 years $(S D=9.52$, Range $=22$ to 72 ). The total sample $(\mathrm{N}=375)$ had a mean age of 41.6 years (SD $=12.46$, Range $=22$ to 84 ). The total group could also be divided into Pharmacists $(\mathrm{N}=200$, Mean age $=39.46, \mathrm{SD}=12.70$, Range $=22$ to 84$)$ and Accountants $(\mathrm{N}=175$, Mean age $=44.05, \mathrm{SD}=11.95$, Range $=24$ to 82 years $)$. Of the total sample $(\mathrm{N}=375) 98.4 \%$ had either Afrikaans $(\mathrm{N}=158$ or $42.1 \%)$ or English $(\mathrm{N}=211$ or $56.3 \%)$ as home language. The home language of one participant was unknown. One, two and two participants had respectively Venda, Zulu and North Sotho as their home language.

Of the total sample 201 participants $(53.6 \%)$ saw themselves working as employees in organizations while $169(45.1 \%)$ were working as private practitioners. Five participants did not indicate whether they were working as private practitioners or as employees. The number of jobs held by participants prior to the study varied between one and eight. Ninety-three percent of the participants had held five or fewer jobs during their career prior to the study. The number of years worked up to the time of the study varied between one and sixty. The mean number of years worked was $18.7(\mathrm{SD}=12.56)$. Members of the sample had worked for an average of 2.83 ( $\mathrm{SD}=1.56$ ) organizations before participating in the present study. The majority of the participants i.e. 295 or 78.7 percent, were married with, respectively 62 ( 16.5 percent), 10,6 and 2 indicating that they were divoreed, widowed or cohabiting. The majority of the participants $(77.6 \%)$ grew up in an urban environment. The majority $(56.8 \%)$ of the participants grew up in the Gauteng Province of South Africa with a more or less even spread over the other eight provinces. 


\section{Procedure}

Systematic sampling was done from the professional registers of pharmacists and accountants. Only members of these occupational groups residing in the main areas of economic activity in South Africa, i.e. the Western Cape and Gauteng, were included in the sample. In total 1210 questionnaires were distributed, 1110 in Gauteng and 100 in the Western Cape. A total of 418 completed questionnaires were received back. Of this number 375 were used in the analysis. Completed questionnaires, in which one or more items in any of the psychometric instruments had not been responded to, were left out of further analysis.

The study was carried out as a postal survey. The various measuring instruments and the questions about demographic variables were combined into one questionnaire, and mailed to the individuals who had been selected to be part of the sample. A reminder letter was sent out one week after the questionnaire had been mailed. A second reminder letter was sent one month after the first mailing.

The responses to the different measuring instruments were, where applicable, subjected to psychometric investigation in order to determine the construct validity of each instrument when applied to members of the present sample. This was done as an attempt to eliminate error variance due to measurement error as far as possible. Exploratory Factor Analysis in the form of Principal Factor Analysis with Direct Quartimin rotation was used for this purpose. The final factor structures were in all cases subjected to Confirmatory Factor Analysis in order to determine the fit between the data and the factor structure. More information on how these procedures were carried out is given in Van Wyk (1998)

\section{Measuring instruments}

The primary purpose of the study was to determine whether Type A behaviour was related to the demographic and personality variables identified in the introduction.

The demographic information that participants were asked to provide were: gender, occupation, home language, employment, marital status, area of birth, province of birth, age, number of jobs held, number of years worked, and number of organizations to which the individual had been attached.

Locus of control was the first personality characteristic that was assessed and related to Type $A$ behaviour. This variable was measured by means of a 
questionnaire developed by Schepers (1995), based on the responses of firstyear university students. This instrument measures, according to Schepers (1995), three factors, namely belief in internal locus of control, belief in external locus of control and thirdly autonomy. Schepers found Cronbach Alpha coefficients of $.83, .84$ and.87 for, respectively, the internal, external and autonomy scales. In the present study 23 of the items in the questionnaire were excluded due to the findings of the Exploratory Factor Analysis. A three-factor solution was finally accepted. The three factors respectively contained 38,14 and five items and had Cronbach Alphas of $.91, .78$ and .84 . The factors were identified as internal locus of control, External locus of control and Vicissitudes of life.

The second personality characteristic measured was Career orientation, a notion developed by Schein (1978). Career orientation was measured by means of the Career Orientations Inventory (Schein, 1995). This instrument is supposed to measure eight orientations, namely Managerial competence, TechnicalFunctional competence, Entrepreneurship, Security, Lifestyle Integration, Pure Challenge, Service dedication and Autonomy/Independence. Recent internal reliability information was not available for the version of the instrument used in the present study. The Exploratory Factor Analysis carried out on the responses of the present sample indicated the presence of only four identifiable factors. These factors were labeled Service Dedication (11 items), Job Security (five items), Entrepreneurship (five items) and Lifestyle Integration (three items). The Cronbach Alpha coefficients for the four factors were, respectively, $.86, .81, .80$ and .72 .

The third characteristic that was measured was job involvement. Kanungo's Job Involvement Inventory (1982) was used to measure this variable. This instrument measures, according to Kanungo (1982), job involvement as a unidimensional factor with a Cronbach Alpha coefficient of .81 . Exploratory Factor Analysis carried out on the responses of the participants in the present study indicated that a one-factor solution with all the items loading $>.35$ could be accepted. The single factor had a Cronbach Alpha coefficient of .88 .

The Minnesota Satisfaction Questionnaire (Weiss, Davis, England and Lofquist, 1967) was used to assess the job satisfaction levels of participants. This short form of the original questionnaire consists of 20 items, measuring two factors, namely intrinsic and extrinsic satisfaction. According to the authors the intrinsic scale has a Cronbach Alpha coefficient of .86. The corresponding figure for the extrinsic scale is .80 . The scale has been evaluated for use on South African samples (Boshoff \& Hoole, 1998; Kamfer, Venter \& Boshoff, 1998). The Exploratory Factor Analysis carried out on the responses in the present sample yielded three factors, identified as general job satisfaction, intrinsic job 
satisfaction and satisfaction with supervision. The three scales consisted of, respectively, six, six and two items. The Cronbach Alpha coefficients were, respectively, $.82, .82$ and .85 .

Self-concept was measured by means of the Six-factor Self-concept Scale developed by Stake (1994). The scale measures, according to Stake (1994), six factors, labelled as Power, Morality, Likeability, Task accomplishment, Vulnerability and Giftedness. Test-retest reliabilities varied between .74 and .88 . In the present study four of the 36 items as developed by the author of the instrument were eliminated during the Exploratory Factor Analysis, yielding a three-factor solution. The factors were identified as Power, Task accomplishment and Likeability. The three factors had Cronbach Alpha coefficients of, respectively, $.85, .84$ and .84 . Factor one contained 14 items, factor 2 contained 12 items and factor three six items.

To measure entrepreneurial orientation, the Entrepreneurial Attitude Orientation Scale developed by Robinson, Stimpson, Huefner and Hunt (1991) was used. The scale measures, according to the authors, four constructs or entrepreneurial attitudes to business, i.e. towards achievement, self-esteem, personal control and economic innovation. According to the authors the sub-scales had test-retest reliabilities of, respectively, $.76, .76, .71$ and .85 . The Cronbach Alpha values were $.84, .73, .70$ and .90 , respectively. After Exploratory Factor Analysis carried out on the responses of the participants in the present study, a threefactor solution was accepted. The three factors (with their respective Alpha coefficients) were identified as attitude towards economic innovation (.90), achievement/personal control (.80) and self-esteem (.77), and respectively contained 29,21 and 12 items. Thirteen of the items in the original questionnaire did not load satisfactorily on any of the newly defined factors.

Type A behaviour was assessed by means of a shortened form of the Jenkins Activity Survey developed by Spence, Helmreich and Pred (1987). According to the authors, two factors are measured by means of this form of the instrument. The factors (and their Cronbach Alphas) are Achievement striving (.79) and, Impatience-irritability (.65). Exploratory Factor Analysis on the responses of the participants in the present study yielded three factors consisting of five, four and three items respectively. The three factors were named achievement, hard driving/competitive, and speed/impatience. Possibly due to the shortness of the sub-scales, the Alpha Coefficients of the three scales were only $.65, .52$ and .49 . Confirmatory Factor analysis was carried out on the three-factor structure. The indices showed a satisfactory fit between the measurement model and the data. The Goodness of Fit index was .93 . 
After the psychometric investigation of the scales, statistical analyses were done to determine whether relationships existed between the Type A scores and the responses to the variables included in the study.

\section{RESULTS}

To determine whether relationships existed between the scores of the participants on the three sub-scales measuring Type A behaviour and the demographic variables, which were measured on categorical scales, MANOVA was used to assess whether different biographic groups differed in terms of their scores on the Type A sub-scales. Groupings that were too small to be subjected to the relevant statistical procedures were left out of the analyses. This happened, for instance, in the case of home language groups other than the Afrikaans and English. Significant overall differences were found among the scores of gender $(F(3 ; 371)=7.49, p=.0001)$, occupation $(F(3 ; 371)=5.66, p=$ $.0008)$, language $(F(3 ; 367)=3.50, p=.002)$, employment $(F(3 ; 366)=4.14, p=$ $.0066)$ and marital status $(F(3 ; 371)=3.72, p=.01)$ groups.

The unidimensional analyses that formed part of the MANOVAS carried out, yielded a significant difference $(F(1 ; 367)=6.55, p=.01)$ between the scores of respondents with Afrikaans and English as home languages on the Type A subscale achievement. Afrikaans speakers had higher scores than English speakers.

Demographic groups formed in terms of gender $(F 1 ; 373)=16.06, p=.0001$ ), occupation $(\mathrm{F}(1 ; 373)=14.15, \mathrm{p}=.0002)$, employment situation $(\mathrm{F}(1 ; 368)=$ $11.15, p=.0009)$ and marital status $(F(1 ; 373)=4.05, p=.05)$, differed significantly from each other on the Type A sub-scale measuring hard-driving competitive behaviour. Males had higher scores than females, accountants higher scores than pharmacists, self-employed individuals higher scores than respondents working as employees in organizations and married persons higher scores than individuals who were unmarried. On the third sub-scale measuring Type A behaviour, i.e. Speed/impatience, accountants had higher scores than pharmacists $(F(1 ; 373)=4.21, p=.04)$, English speakers higher scores than A frikaans speakers $F(1 ; 367)=7.26(p=.007)$ and married respondents higher scores than those who were unmarried $(F(1 ; 373)=8.00, p=.005)$. On the total Type A score significant differences were found between occupational groups $(F(1 ; 373)=6.94, p=.009)$, with the scores of accountants higher than those of pharmacists. Married respondents also had a significantly higher score than unmarried persons on the total Type A scale $(F(1 ; 373)=6.30, p=.01)$.

The relationships found up to this stage of the analysis were, even when significant, not very strong. The value of R-squared in no case exceeded $4.5 \%$. To determine whether the findings could be interpreted as conceptually 
important, Discriminant Analyses were carried out. This was done in two phases. A Discriminant model was built by means of the Stepdisc procedure in SAS using Type A sub-scale scores as discriminants. This model was then used, by means of Proc Discrim in SAS, to categorize respondents into demographic subgroups. The results indicated that the discriminations achieved were generally poor. The model developed to predict membership of gender subgroups included the Achievement and Hard driving/competitive sub-scales of Type A behaviour. Only $58.4 \%$ of male respondents and $52.6 \%$ of female respondents were placed correctly by the model. The Afrikaans/English division was predicted by means of a model in which the Achievement and Speed/Impatience sub-scales were included. Only $57.3 \%$ of respondents with English and $59.5 \%$ of those with Afrikaans as home language were placed correctly. Of the accountants in the sample $57.1 \%$ were placed correctly using a model in which only the hard driving/competitive sub-scale could be included. The corresponding figure for pharmacists was $53.0 \%$. Private practitioners were placed correctly at the level of $58.6 \%$, while $54.7 \%$ of respondents working as employees were categorized correctly by means of a model containing only the hard driving/competitive sub-scale. Of unmarried respondents, $71.8 \%$ could be correctly categorized by means of a model in which only Speed/impatience was included. For married respondents, however, the figure was $43.8 \%$.

Calculating product-moment correlation coefficients tested the relationships between biographical variables measured on continuous scales and scores on the Jenkins scale and sub-scales. A significant correlation (.11) was obtained in the case of the relationship between age and the Speed/impatience sub-scale. The number of jobs held correlated .14 with both the Hard driving/Competitive subscale of the Jenkins Activity Scale, and with the Jenkins total score. The relationship between age and the scores on the Jenkins scale and sub-scales was investigated further, as it was thought that the relationships could possibly be non-linear with older respondents scoring lower on Type A behaviour than younger ones. For this purpose two age groups, including respondents up to the age of 40 years and those over the age of 40 , respectively were formed. Oneway Analysis of Variance was used to determine whether the scores of the two age groups differed on the Jenkins scale and sub-scales. Only one significant difference was found, namely that between the scores of the two groups on the Hard driving/Competitive sub-scale $(F(3 ; 371)=5.91, p=.0006)$. The older age group had a significantly lower score than the younger group. This result must be interpreted with caution, as the Analysis of Variance procedure is not robust against large numbers in the comparison groups.

The relationships between Type A behaviour and the variables that were measured on psychometric scales, were first investigated by calculating Pearson Product moment correlation coefficients between the scores on the Type A 
behaviour scale and sub-scales, and the scores on the different variables as identified through factor analysis described earlier. Of the 17 correlation coefficients calculated between scale and sub-scale scores and the Jenkins subscale measuring achievement, 11 were significant at the $95 \%$ confidence level. The scale and sub-scales that yielded significant correlation with the achievement sub-scale were (with the values of $r$ in brackets): Internal locus of control (.34), Service dedication (.36), Job security (.15), Job involvement (.27), General job satisfaction (.16), Intrinsic job satisfaction (.15), Power (.31), Task accomplishment (.29), Economic innovation (.34), Achievement/Personal control (.29), and Self-esteem (-.11). Fourteen of the correlation coefficients between sub-scale scores and the Hard-driving/competitive Type A behaviour sub-scale were significant at the $95 \%$ confidence level. These coefficients were: Internal locus of control (.40), External locus of control (-.21), Service dedication (.23), Job security $(-.18)$, the Entrepreneurship career orientation (.20), Job Involvement (.19), General job satisfaction (.24), Intrinsic job satisfaction (.15), Power (.48), Task accomplishment (.12), Likeability (.16), Economic innovation (.35), Achievement/Personal control (.21), and Selfesteem (-.32). At the $95 \%$ confidence level five of the 17 correlations between sub-scale scores and the Type A sub-scale measuring Speed/Impatience were signiticant. The significant coefficients were: Internal locus of control (.11), Vicissitudes of life (.13), Entrepreneurship (.18), Supervision (-.12), Power (.13). The total Type A score correlated significantly with: Internal locus of control (.47), Service dedication (.38), the Entrepreneurship career orientation (.20), Job involvement (.29), General job satisfaction (.25), Intrinsic job satisfaction (.19), Power (.49), Task accomplishment (.26), Economic innovation (.44), Achievement/Personal control (.31) and Self-esteem (-.23).

To further investigate the relationships, Multiple Regression Analysis was used. The scores on the different sub-scales in the psychometric instruments were used as the predictor variables, and the Type A sub-scales and the total Type A score as the dependent variables. The prediction model contained eleven independent variables (Dedication to service, Task accomplishment, Likeability, Power, Job security, Economic innovation, Internal locus of control, External locus of control, General job satisfaction, and Entrepreneurship (career orientation) in the case of the dependent variable Type A Achievement. The common variance amounted to $36.05 \%$. The model to predict the sub-scale Hard driving/competitive contained the Power, General job satisfaction, Internal locus of control, and the Job Security variables. The common variance amounted to $27.15 \%$. The third Type A sub-scale (Speed/Impatience) scores were predicted by a model containing the variables Entrepreneurship career orientation and the Vicissitudes of life sub-scale. The common variance in this case was only $4.56 \%$. The total Type A score was predicted by a model containing the variables Power, Internal locus of control, Likeability, External locus of control, 
Achievement/personal control, General satisfaction, Task accomplishment and, finally, Job Involvement. The common variance in this case was $40.30 \%$.

\section{DISCUSSION}

In order to place the results obtained in perspective, the findings of the present study are compared to those of previous research. The results regarding the relationships between Type $A$ behaviour and biographical variables are discussed first.

In the present study, it was found that older respondents had lower scores on the Hard driving/competitive sub-scale of the Jenkins Activity Survey. Similar results were obtained by Friedman and Rosenman (1974), Blumenthal and Herman (1985), Helman (1987), Strümpfer (1988) and by Dielman et al. (1990). Jamal and Baba (1992) obtained the opposite result in their study of the level of Type A behaviour in nurses. The possibility that the occupation of respondents might be a confounding factor as far as the relationship is concerned must be considered in interpreting these results, but the present evidence suggests that Type $\mathrm{A}$ behaviour tends to decrease with age.

An overall difference between the Type A score profiles of men and women was found in the present study. The uni-dimensional analysis revealed a significant difference between the scores of men and women on the hard driving competitive sub-scale of the Jenkins Activity Survey, with men scoring higher than women. A similar finding was made by Bedeian et al. (1990). The opposite result was obtained in several other studies (Burke, 1983; Sorenson et al., 1987; Wiegele and Oots, 1990; Greenglass, 1993; Byrne and Reinhart, 1995). The possibility of confounding variables, like differences in the composition of samples, influencing the results of studies must be considered in coming to a conclusion in this regard. It seems as if the conflicting results warrant further research.

The finding that accountants scored higher than pharmacists on Type A behaviour seems to confirm a finding in this regard by Strümpfer (1993). Studying respondents from different language groups Strümpfer (1993) found that Afrikaans speakers scored significantly higher than English speakers on a measure of Type A behaviour. In the present study it was found that Afrikaans speakers scored higher than English speakers on the Achievement sub-scale. The opposite was true for the Speed and Impatience sub-scale. The relationship between home language and Type $\mathrm{A}$ behaviour therefore does not seem to be a straightforward one. 
In the present study it was found that respondents who were self-employed scored higher than those who worked for somebody else. This result may point to the existence of a self-selection process with hard driving and competitive individuals entering private practice rather than to be employed by others. Type A behaviour can, as Van Wyk (1998) pointed out, be a behaviour pattern that may be useful in the business world.

Significant relationships were also obtained between the number of jobs held and the number of working years on the one hand and Type $A$ behaviour on the other. These were, however, very weak relationships with the common variance not exceeding 3\%. Married respondents tended to have higher scores on the Type A measure. This is in accordance with the findings of Byme and Reinhart (1995).

The findings that scores on the Achievement sub-scale of the Jenkins Activity Survey and the Internal Locus of Control sub-scale correlated positively ( $r=$ .40) with each other, and that both the variables internal and external locus of control entered into the Multiple Regression model in which Achievement was the dependent variable, are in accordance with findings by Furnham (1983), Volkmer and Feather (1991) and by Spector and O'Connel (1994). These relationships therefore now seem to be well established.

The Hard driving/Competitive sub-scale of the Jenkins Activity Survey showed a statistically significant positive relationship with Internal locus of control $(r=$ $-.40)$ and a significant negative correlation $(r=-.21)$ with External locus of control. Internal locus of control also entered into the Multiple Regression model with the Hard driving/Competitive Type A sub-scale as dependent variable.

The Speed/Impatience sub-scale of the Jenkins Scale showed statistically significant positive relationships with Internal locus of control and with Vicissitudes of life. These were, however, weak relationships, containing only $1.2 \%$ and $1.7 \%$ common variance. Volkmer and Feather (1991) found the opposite - a weak negative relationship between Speed /mpatience and Internal locus of control. The different results and the low strength of the relationships that were found probably indicate that the results should be seen as inconclusive.

The Jenkins total score showed a statistically significant relationship only with Internal locus of control $(r=.47)$. Both the Internal and External locus of control sub-scales were included in the Multiple Regression Model predicting Jenkins total score. These findings are in agreement with those of Volkmer and Feather (1991) and Morrison (1997). Gomez however found the opposite 
(1997). The results cited seem to indicate that Locus of control is probably related to Type A behaviour.

In a previous study (Burke, 1983), the Managerial career orientation correlated with the Job Involvement and Hard driving sub-scales as well as with the total score on the Jenkins Activity Survey. This result is difficult to compare with those obtained in the present study, as the factorial structure of the instrument used for measuring career orientations differed considerably from that used in previous studies. (This indicates how difficult it is to do rigorous quantitative intercultural research when the available measuring instruments have only been standardised in one country.) In the present study it was found that significant positive relationships existed between the Achievement sub-scale of the Jenkins Activity Survey and the Dedication to Service and Job Security career orientations. The Job Security/Achievement relationship was not strong as only $2 \%$ common variance was found to exist. The Multiple Regression model for the prediction of scores on the Achievement sub-scale contained the career orientations Service, Job Security and Entrepreneurial. The scores on the Service, Job security and entrepreneurial orientations correlated significantly with scores on the Hard driving/Competitive Jenkins sub-scale. These were weak correlations, the common variance being, respectively, $4.8 \%, 3.2 \%$ and $3.6 \%$. Job security was inciuded in the Multiple Regression model for the prediction of Hard driving/Competitive scores. The Entrepreneurial career orientation scores correlated significantly with the Speed and Impatience subscale scores. The relationship was not strong as the common variance amounted to only $2.9 \%$. The same orientation was included in the Multiple Regression model developed for the prediction of Speed and Impatience scores. The total score on the Jenkins scale correlated .38 with the Service career orientation and .20 with the Entrepreneurial orientation. None of the career orientations was included in the model built to predict the total Type A scores.

In the present study, Job involvement scores related statistically significantly with the scores on the Achievement sub-scale, the Hard driving/Competitive sub-scale and with the total Type A score, with the common variances being only $7.3,3.6$ and $7.8 \%$ respectively. Job involvement also entered into the Multiple Regression model predicting the total Type A score. Chusmir and Hood (1986) and (1988) obtained similar results. It seems as if a rather weak but statistically significant relationship exists between Job involvement and some aspects of Type $\mathrm{A}$ behaviour.

The relationship between job satisfaction and Type $\mathrm{A}$ behaviour has been investigated in several studies. The results were contradictory. Chursmir and Hood (1988), Byrne and Reinhart (1990), Gamble and Matteson (1992) as well as Byrne and Reinhart (1994), found negative relationships between at least 
some facets of Type A behaviour and job satisfaction, The opposite i.e. a positive relationship, was found by Bedeian, et al. (1990), Day and Bedeian (1991), Kushnir and Melamed (1991) and Norden (1995). In the present study low but significantly positive relationships between some Type A facet scores and some of the sub-scales of job satisfaction were found. A low but significantly negative relationship was observed between the Supervision subscale of the MSQ as identified in the present study and the Speed/Impatience Type A sub-scale. A final conclusion on the relationship between job satisfaction and Type $A$ behaviour can therefore not be drawn at this stage. The relationships found in different studies were not strong and appear to be rather contradictory.

In the present study, four dimensions of the Self-concept scale used were identified. Scores on these factors were related to the scores on the Type A subscales and the total Type A score. It was found that scores on the Achievement sub-scale of the Jenkins Activity Survey correlated significantly positive with the scores on the self-concept factor identified as Power and with the Task Accomplishment/Morality self-concept factor. The common variances amounted to 9.7 and $8.4 \%$ respectively. With Achievement as dependent variable the Task Accomplishment and Likeability factors were included in the Multiple Regression model. The Hard driving/Competitive sub-scale correlated statistically significantly with al three of the self-concept sub-scales. The percentages of common variance were, respectively, 22.1\% (Power), 1.7\% (Task Accomplishment/Morality) and 2.6\% (Likeability). Only the Power sub-scale entered into the Multiple Regression model with Hard driving/Competitive as dependent variable. It seems as if only the relationship between Power and the Hard driving/Competitive relationship is of real significance. The Power subscale also correlated statistically significantly with the Speed/Impatience Type A sub-scale. The common variance at $1.7 \%$ was also low. The total score of the Jenkins Activity Survey showed two significant relationships with Self-concept factors i.e. with Power $(24 \%$ common variance $)$ and with Task Accomplishment/Morality (6.8\% common variance). When the Jenkins Activity Survey total score was used as the dependent variable in the Multiple Regression Analysis, the Task Accomplishment/Morality and the Likeability sub-scales were included in the model. The findings with regard to the relationship between dimensions of the self-concept and Type $A$ behaviour seem to contradict the results of previous studies in which it was found that Type $A$ behaviour was associated with lower rather than higher self-esteem (Wolf et al., 1981; Lobel, 1988). The opposite tendency was found in the present study, i.e. a positive relationship between Type $A$ behaviour and self-concept scores. The interpretation of this result is at present not unclear. It might be speculated that respondents higher in Type A behaviour may be more successful in their occupations and in life generally and therefore have a more positive self-concept 
than those lower in Type $A$ behaviour. This presupposes a relationship between Type A behaviour and success, which has not been proved yet.

In the present study, the possible relationship between Type A behaviour and entrepreneurial attitudes was also investigated. Significant but relatively weak correlations were obtained between the Achievement sub-scale of the Type A measure and attitude to Economic Innovation (11.6\% common variance); attitude to Achievement/Personal Control ( $8.4 \%$ common variance); and attitude to self-esteem (negative relationship, $1.2 \%$ common variance). Attitude towards Economic Innovation was included in the Multiple Regression model with the Type A Achievement sub-scale as dependent variable. The Hard driving/Competitive Type A sub-scale also related significantly to all the subscales of the Entrepreneurial Attitude Orientation Scale (EAOS). The common variances were: Economic Innovation, 12.3\%; Achievement/Personal control, $4.4 \%$; Self esteem, $9.6 \%$. The relationship between Self-esteem and Hard driving/Competitive was found to be negative $(r=-.32)$. The total scale score on the Jenkins Activity Survey showed significant relationships with Economic Innovation (19.4\% common variance), Achievement/Personal Control $(9.6 \%$ common variance) and Self-esteem (5.3\% common variance). The relationship between attitude towards self-esteem and the total Type $A$ score was negative. These findings cannot be related to those of previous studies, as no such studies could be found. It does seem as if the finding with regard to the relationship between self-esteem and Type $A$ behaviour, which was found in the present study, is in accordance with earlier findings as stated earlier.

The Multiple Regression models built to predict the scores on the sub-scales and the total score of the Jenkins Activity Survey, represented a first attempt of this nature. The results were encouraging. It could be shown that scores on the Jenkins sub-scale Achievement could be predicted quite well by means of scores on the sub-scales of the psychometric instruments used in the present study. Common variance of $40.30 \%$ between the scores on this scale and predictors included in the Multiple Regression model, seems to indicate that a definite relationship was established between Type $A$ behaviour and the variables included in the model.

The primary contribution of the present study seems to be the determination of the relationships among a number of variables in the work situation, in this case of professional people. Although limited, the sample was carefully defined and seemed to represent a clear statistical set. The results indicate that a substantial proportion of the variance in Type A behaviour can be explained by means of the variables measured in this study. 
The present study seems to have broadened the view of the relationships of different variables with Type A behaviour in the work environment. The Multiple Regression Analyses showed Type A behaviour to be related to various self-concept constructs, e.g. Locus of control, self-esteem as measured by the Self-concept Scale and the individual's Career self-concept as measured by means of the Career Orientations Inventory. Self-perception therefore seems to be involved in the development and maintenance of Type A behaviour.

The relationship between Type A behaviour and entrepreneurial attitude has, as far as could be determined, been investigated for the first time. The analyses indicated that entrepreneurial orientations seem to be related to Type $A$ behaviour to a significant extent.

This study carefully investigated of the measurement qualities of the instruments by the revalidation of each of the measuring instruments used. It could be shown that several of the instruments did not stand up well to revalidation on a South African sample. The importance of scepticism about the validity and reliability of instruments developed in one culture, and used on members of another culture is emphasized by these results. The study also seems to represent a contribution to our knowledge of the correlates of Type A behaviour in a culture different from the North American one, where the majority of such studies has until now been done.

The study has clear limitations. The results must be interpreted with caution due to the low values of the Cronbach Alpha coefficients of the sub-scales of the Type A measurement. The study was done on individuals in only two professional categories and the findings can therefore not be generalized to other occupational groups too.

It seems advisable to use a longer version of the Jenkins Activity Survey in future studies, and to carefully revalidate the instrument before utilizing it as a criterion measure. More information on the psychometric qualities of measuring instruments when used in cultures different from those in which they were developed, seems essential in future research of this nature.

Future studies should be aimed at professionals other than accountants and pharmacists. Considerable further analysis of the data gathered in this study is possible, and is also currently being undertaken. 


\section{REFERENCES}

1. ADLER, N. \& MATTHEWS, K. (1994) Health Psychology: Why do Some People Get Sick and Some Stay Well?, Annual Review of Psychology, 45: 229-59.

2. ANASTASI, A. (1990) Psychological Testing, New York: Macmillan.

3. BEDEIAN, A.G., MOSHOLDER, K.W. and TOULIATOS, J. (1990) Type A Status and Selected Work Experiences Among Male and Female Accountants, In: Strube, M.J. (Ed.) Type A Behoviour; 261-75, Newbury Park: Sage.

4. BEGLEY, T.M. (1995) Using Founder Status, Age of Firm, and Company Growth Rate as the Basis for Distinguishing Entrepreneurs from Managers of Smaller Businesses, Journal of Business Venturing, 10: 24963.

5. BLUMENTHAL, J.A. \& HERMAN, S. (1985) "Age Differences in SelfPerceptions of Type A Traits", Journal of Consulting and Clinical Psychology: 53(3): 264 -6.

6. BOSHOFF, A.B. \& HOOLE, C. (1998) "Portability of the Job Involvement and Job Satisfaction Constructs between the United States of America and South Africa", South African Journal of Economic and Management Sciences, 1(1) New series: 73-84.

7. BURKE, R.J. (1983) "Career Orientations of Type A Individuals", Psychological Reports, 53(3): 979-89.

8. BURKE, R.J. (1985) "Career Orientations and Type A Behavior in Police Officers", Psychological Reports, 57: $1239-46$.

9. BYRNE, D.G. (1987) The Behavioral Management of the Cardiac Patient, New Jersey: Abex.

10. BYRNE, D.G. \& BYRNE, A.E. (1990) "Occupational Stress, Type A Behavior and Risk of Coronary Disease", Work and Stress, 4(2): $155-66$.

11. BYRNE, D.G. \& REINHART, M.I. (1994) "Type A Behaviour, Job Satisfaction and Risk of Coronary Heart Disease", Stress Medicine, 10: 223-31.

12. BYRNE, D.G. \& REINHART, M.I. (1995) "Type A Behaviour in the Australian Working Population", Australian and New Zealand Journal of Psychiatry, 29 (2): $270-7$.

13. CHUSMIR, L.H. \& HOOD, J.A. (1986) "Relationship Between Type A Behavior Pattern and Motivational Needs", Psychological Reports, 58(3): 783-94.

14. CHUSMIR, L.H. \& HOOD, J.A. (1988) "Predictive Characteristics of Type A Behavior among Working Men and Women", Journal of Applied Social Psychology, 18(8): 688-98. 
15. COX, J.J. (1983) Coronary Prone Behaviour and its Relationship to Stress in a South African Environment, Masters' thesis, University of Witwatersrand.

16. DAY, D. V. \& BEDEIAN, A.G. (1991) "Work Climate and Type A Status as Predictors of Job Satisfaction: A Test of the Interactional Perspective", Journal of Vocational Behavior, 38: 39-52.

17. FEATHER. N.T. \& VOLKMER, R.E. (1988). "Preference for Situations Involving Effort, Time Pressure, and Feedback in Relation to Type A Behavior, Locus of Control and Test Anxiety", Journal of personality and social Psychology, 55(2): 266-71.

18. FORSHAW, B.M. (1984) Occupational Stress: Type A Behaviour as A Moderator of the Relationships Between Role Demands and Psychological and Behavioural Strain, Masters' dissertation: University of Cape Town.

19. FRIEDMAN, M. \& ROSENMAN, R.H. (1959) "Association of Specific Overt Behavior Pattern with Blood and Cardiovascular Finding: Blood Cholesterol Level, Blood Clotting Time, Incidence of Arcus Senilis and Clinical Coronary Artery Disease", Journal of American Medical Association, 169: 1286-96.

20. FRIEDMAN, M. \& ROSENMAN, R.H. (1974) Type A Behavior and Your Heart, New York: Knopf.

21. FURNHAM, A. (1983) "The A Type Behaviour Pattern, Mental Healthy and Health Locus of Control Beliefs", Social Science and Medicine, 17(20): 1569-72.

22. GAMBLE, G.O. \& MATTESON, M.T. (1992) "Type A Behavior, Job Satisfaction and Stress Among Black Professionals", Psychological Reports, 70: 43-50.

23. GOMEZ, R. (1997) "Locus of Control and Type A behavior Pattern as Predictors of Coping Styles Among Adolescents", Personality and Individual Differences, 23(3), 391-8.

24. GREENGLASS, E.R. (1991) "Type A Behavior, Career Aspirations, and Role Conflict in Professional Women", In: Strude, M.J. (Ed.), Type A Behavior, Newbury Park: Sage: 277-92.

25. GREENBLASS, E.R. (1993) "Structural and Social Psychological Factors Associated with Job Functioning by Women Managers", Psychological Reports, 73: 979-86.

26. HARTEL, U. \& CHAMBLESS, L. (1989) "Occupational Position and Type A Behavior:Results from the First MONICA Survey, Augsburg, F.R.G.", Social Science Medicine, 29(12): 1367-72.

27. HELMAN, C.G. (1987) "Heart Disease and the Cultural Construction of Time: the Type A Behavior Pattern as a Western Culture-Bound Syndrome", Social Science and Medicine, 25(9): 969-79. 
28. HICKS, R.A. OLSEN, C. \& SMITH-ROBISON, D. (1986) "Type A-B Behavior and The Premenstrual Syndrome", Psychological Reports, 59: 353-4.

29. JAMAL, M. (1985) "Type A Behavior and Job Performance: Some Suggestive Findings", Journal of Human Stress, 11(2): 60-8.

30. JAMAL, M. \& BABA, V.V. (1991) "Type A Behaviour, its Prevalence and Consequences Among Women Nurses: An Empirical Examination", Human Relations, 44 (11): 1213-28.

31. JENKINS, C.D., ZYZANSKI, S.J. and ROSENHAM, R.H. (1979) Jenkins Activity Survey: JAS Manual, New York: The Psychological Corporation.

32. KAMFER, L., VENTER, D. and BOSHOFF, A.B. (1998) "The Portability of American Job Involvement and Job Satisfaction Scales to Non-English Speaking South Africans", South African Journal of Economic and Management Sciences, New series 1(1): 85-107.

33. KANUNGO, R.N. (1982) "Measurement of Job and Work Involvement", Journal of Applied Psychology, 67(3): 341-9.

34. KUSHNIR, T. \& MELAMED, S. (1991) "Work-Load, Perceived Control and Psychological Distress in Type A/B Industrial Workers", Journal of Organizational Behavior, 12: 155-68.

35. McCORMICK, E.J. \& ILGEN, D. (1985) Industrial and Organizational Psychology ( $8^{\text {th }}$ ed.), London:Allen \& Unwin.

36. MORRISON, K.A. (1997) "Personality Correlates of the Five-Factor Model for a Sample of Business Owners/Managers: Associations with Scores on Self-Monitoring, Type A Behavior, Locus of Control, and Subjective Well-Being", Psychological Reports, 80: 255-72.

37. MUGDIL, Y., MUHAR, I.S. and BHATIA, P. (1992) "Low Job Satisfaction and Type A Behaviour Pattern", Journal of the Indian Academy of Applied Psychology, 18(1-2): 19-22.

38. NORDEN, B. (1995) Type A Components, Perceived Control and Related Outcomes, Masters' dissertation: University of the Witwatersrand.

39. ROBERTSON, I.T., COOPER, C.L. and WILLIAMS, J. (1990) "The Validity of the Occupational Stress Indicator", Work and Stress, 4: 29-39.

40. ROBINSON, P.B., STIMPSON, D.V., HUEFNER, J.C. and HUNT, K.N. (1991) "An Attitude Approach to the Prediction of Entrepreneurship", Entrepreneurship:Theory and Practice, 15(4): 13-31.

41. ROSENMAN, R.H. (1991) Type A behavior Pattern: A Personal Overview. In: Strube, M.J. Type A behavior (1-24), Newbury Park: Sage.

42. SCHEIN, E.H. (1978) Career Dynamics: Matching Individual and Organizational Needs, Boston MA: Addison-Wesley Publishing Company.

43. SCHEIN, E.H. (1995) Career Orientations Inventory, Englewood Cliffs, NJ: Prentice Hall. 
44. SCHEIN, E.H. \& KOMMERS, D.W. (1972) Professional Education. New York: Mcgraw-Hill.

45. SCHEPERS, J.M. (1995) Locus of Control Inventory. Unpublished Report: Rand Afrikaans University.

46. SORENSON, G., JACOBS, D.R. jr., PIRIE, P., FOLSOM, A., LUEPKER, R., and GILLUM, R. (1987) "Relationships Among Type A Behavior, Employment Experiences, and Gender: The Minnesota Heart Survey", Journal of Behavioral Medicine, 10(4): 323-36.

47. SPECTOR, P.E. \& O'CONNEL, B.J. (1994) "The Contribution of Personality Traits, Negative Affectivity, Locus of Control and Type A to the Subsequent Reports of Job Stressors and Job Strains", Journal of Occupational and Organizational Psychology, 67:1-4.

48. SPENCE, J.T., HELMREICH, R.L. and PRED, R.S. (1987) "Impatience Versus Achievement Strivings in the Type A pattern: Differential Effects on Students' Health and Academic Achievement", Journal of Applied Psychology, 72(4): 522-28.

49. STAKE, J.E. (1994) "Development and Validation of the Six-Factor SelfConcept Scale for Adults", Educational and Psychological Measurement, 54(1): 56-72.

50. STRÜMPFER, D.J.W. (1993) "An Overview of Jenkins Survey data in South Africa", South African Journal of Psychology, 23(3): 134-44.

51. SWANEPOEL, E. (1984) Coronary-Prone Behaviour Among White South African Business Women, MA dissertation: University of the Witwatersrand.

52. THORESEN, C.E. \& LOW, K.G. (1991) "Women and the Type A Behavior Pattem: Review and Commentary", In: Strube, M.J. (Ed.) Type A Behavior. Newbury Park: Sage: 117-33.

53. VAN WYK, R. (1998) The Type A Behaviour Pattern in Professionals, Doctoral dissertation, University of Pretoria.

54. WEISS, E.J., DAWIS, R.V., ENGLAND, G.W. and LOFQUIST, L.H. (1967) Manual for the Minnesota Satisfaction Questionnaire, St. Paul, Minnesota: University of Minnesota.

55. WIEGELE, T.C. \& OOTS, K.L. (1990) "Type A Behaviour and Local Government Elites", Political Psychology, 11(4): 721-37.

56. WOLF, T.M., HUNTER, S., WEBBER, L.R. and BERENSON, G.S. (1981) "Self-Concept, Locus of Control, Goal Blockage, and CoronaryProne Behavior Pattern in Children and Adolescents: Bogalusa Heart Study", The Journal of General Psychology, 105: 13-26. 